\title{
Development of Water Generation System from Air
}

\author{
Sahil Doshi" ${ }^{*}$, Shubham Chaudhari", Saheel Aitwade" ${ }^{\#}$, Ratan Singh", and C. P. Waykole ${ }^{\#}$ \\ \#Department of Mechanical Engineering, MIT College of Engineering, Pune, Maharashtra, 411038, India
}

Accepted 03 March 2016, Available online 15 March 2016, Special Issue-4 (March 2016)

\begin{abstract}
The lack of clean drinking water is one of the key issues facing the world today. The water in many countries is of poor quality creating a big demand for bottled water where the economic means are available. For underdeveloped countries this has led to the death of millions while it in the industrialized world has meant a big increase in consumption of bottled water which has had a big negative effect on the environment. There have been some efforts in trying to develop an applicable technology as a solution to the water problem. One line of products in particular has been influential for this project. These products are known as atmospheric water generators and are trying to utilize the natural occurrence of water vapor in air in order to produce clean drinking water.
\end{abstract}

Keywords: Relative Humidity, Specific Humidity, Dry Bulb Temperature, Dew Point Temperature

\section{Introduction}

Because of pure water scarcity in many regions worldwide, finding alternative methods for pure water generation becomes beneficial enough to motivate many researchers to work on related topics. Atmospheric water generation is one of the promising methods for getting pure water. Atmospheric water generators (AWGs) apply vapour compression refrigeration to extract water vapour from the surrounding air. They produce drinking quality water and they require moist air and electricity.

\section{Purpose}

This thesis is a part of the development of an AWG, for this purpose the project group will initially investigate the suitability of the vapor compression cycle, where the extraction will be obtained on the evaporator. An AWG is a device that generates clean drinking water by utilizing the natural presence of water vapor in the air. This thesis will hopefully result in information that will be used as a basic data for decision-making. Since most of the evaporators on the market today are designed merely to cool the air passing through them, much effort will be made to design an evaporator that not only lower the temperature but also condensate some of the water vapor included in the air and to collect the condensed water if this technology is assessed to be liable. There can also be other technologies that can be more suitable for this application. The main purpose is to investigate which technology is the most suitable one in order to extract water. Other possible solutions for this problem will be presented, explained and discussed. The purpose is to find and develop a technology applicable for water extraction.

*Corresponding author: Sahil Doshi

\section{Problem}

The main objective of this project is to create a product that is able to produce safe and clean drinking water while only consuming air and energy. The problem of this thesis concerns the nature, technology and process of the actual extraction. This report will try to answer how the actual extraction will be performed, what technology will be used and why.

\subsection{Experimentation and Methodology}

Condensation of water vapour from air will be carried out by dehumidification using vapour compression refrigeration cycle

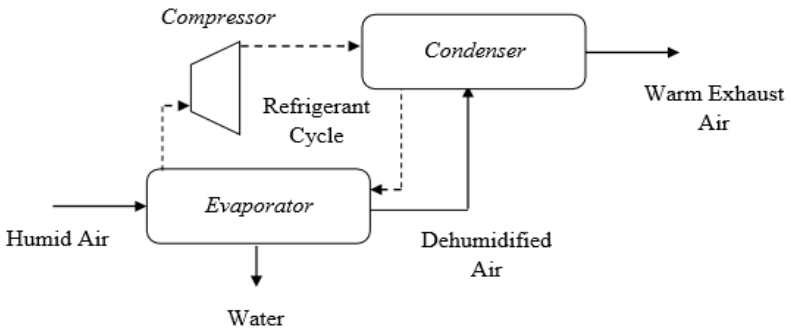

Fig.1 Dehumidification by Vapour Compression Refrigeration cycle

The above figure shows that water suspended in humid air is condensed by passing the humid air over the evaporator coils in Vapour Compression Refrigeration cycle. 


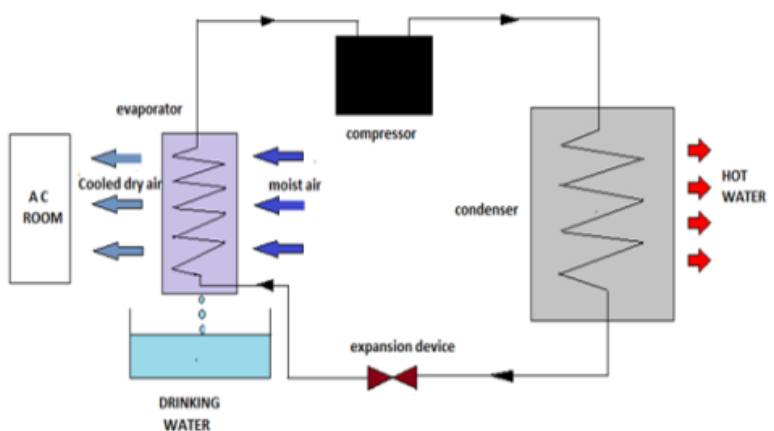

Experimental setup consists of: Compressor, Condensor, Expansion Device, Evaporator, Water Collecting tank, Filtration System

Fig.2 Schematic diagram of Experimental setup

\section{Calculation}

At DBT $=26$ Degree $\mathrm{C} \& \mathrm{RH}=60 \%$

we get dew point temperature $=17.64$ Degree $C$

By taking references from Research papers

Extraction efficiency $=40 \%$

Water extracted $=20 \mathrm{~L}$

Specific humidity $=0.012 \mathrm{~kg}$ of water $/ \mathrm{kg}$ of dry air.

It depicts that $1 \mathrm{~kg}$ of dry air contains $0.012 \mathrm{~kg}$ of water

\& considering $40 \%$ extraction efficiency

from $1 \mathrm{~kg}$ of dry air $0.0048 \mathrm{~kg}$ of water is extracted

Table 1. Quantity of water present in Air

\begin{tabular}{|l|l|l|}
\hline $\begin{array}{l}\text { Water present in } \\
\text { air }\end{array}$ & Water extracted & Dry air \\
\hline $0.0012 \mathrm{~kg}$ & $0.0048 \mathrm{~kg}$ & $1 \mathrm{~kg}$ \\
\hline $50 \mathrm{~kg}$ & $20 \mathrm{~kg}$ & $4166.67 \mathrm{~kg}$ \\
\hline
\end{tabular}

$\mathrm{Cp}$ (air)=1.005 kJ/kg K

Heat absorbed

by refrigerant $=$ heat rejected by air + latent heat of water

$=\mathrm{m}$ (air)Cp.dT $+\mathrm{m}$ (water) $\mathrm{L}$

$=0.48466+0.52$

$=1.0078 \mathrm{~kW}$

Refrigeration effect $=1.0078 \mathrm{~kW}$

Assumptions made

Temp of condenser $=55$ degree $\mathrm{C}$

Outlet to compressor $=60$ degree $\mathrm{C}$

Inlet to compressor $=15$ degree $\mathrm{C}$

Evaporator temperature $=2$ degree $\mathrm{C}$

From P-h chart,

$$
\begin{aligned}
\mathrm{h} 1 & =410 \mathrm{~kJ} / \mathrm{kg} \\
\mathrm{h} 2 & =430 \mathrm{~kJ} / \mathrm{kg} \\
\mathrm{h} 3 & =\mathrm{h} 4=280 \mathrm{~kJ} / \mathrm{kg}
\end{aligned}
$$

i] Heat absorbed during evaporation stage $=m(r)[h 1-h 4]$

ii] mass flow of refrigerant

$$
\begin{aligned}
1.0078 & =\mathrm{m}(\mathrm{r})[410-280] \\
\mathrm{m}(\mathrm{r}) & =0.007752 \mathrm{~kg} / \mathrm{sec}
\end{aligned}
$$

Compressor work $=\mathrm{m}(\mathrm{r})[\mathrm{h} 2-\mathrm{h} 1]$

$$
=0.155 \mathrm{~kW} / \mathrm{hr}
$$

Heat rejected in condenser $=\mathrm{m}(\mathrm{r})[\mathrm{h} 2-\mathrm{h} 3]=1.162 \mathrm{~kW}$

- $\quad$ Power required by compressor $=0.155 \mathrm{~kW}$

- $\quad$ Total hours per month used $=30 \times 24$

- Total units consumed $=30 \times 24 \times 0.155=111.6$ $\mathrm{kWh}$

As per MSEDCL; cost per unit $=6.25 \mathrm{Rs}$

- $\quad$ To run compressor for a month $=111.6 \times 6.25=$ 697.5 Rs

- It will cost around Rs 23.33 per day

- $\quad$ Rs 23.33 for $20 \mathrm{~L}$ of water

- $\quad$ For $1 \mathrm{~L}$ of water, it costs around Rs 1.16

\section{Observation and Result}

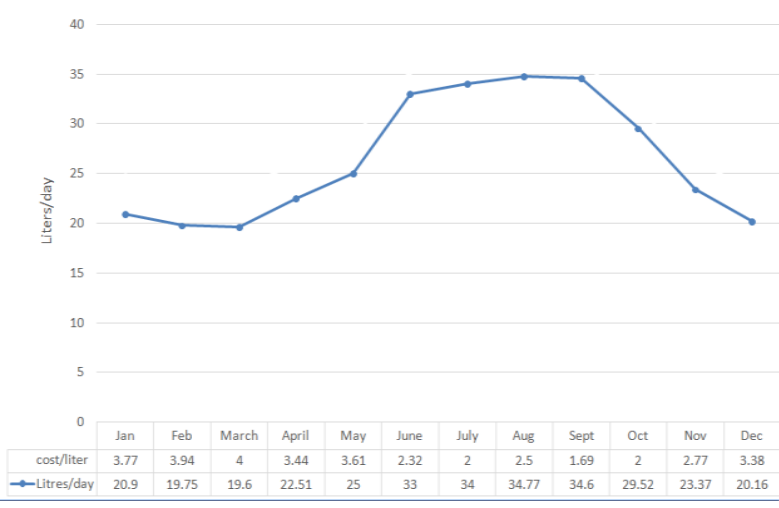

Graph 1 Quantity of water vs cost

\section{Conclusions}

1) This application of this technology may result in solution for water supply problems in many situations without high infrastructure setup cost and time needed.

2) It could create additional potable water without depleting existing resources.

3) Thus it helps us to tackle the problem of availability of pure drinking water in remote locations, mining sites and instances where water scaling is an issue.

\section{References}

Naomi J. Blackburn and greg M. Peters,(2001),Atmospheric water generation- an environmentally friendly alternative to bottled water School of Civil and Environmental Engineering, UNSW Sydney NSW 2052.

David Eriksson and Reza Hashemi,(2008), Evaluation of suitable methods for water generation ,Master of Science Thesis MMK 2008: 43 MCE 160

J.K.Dabas and A.K.Dodeja, October (2011),Performance characteristics of vapour compression refrigeration cycle under real static conditions, International Journal of Advancements in Technology www.ijict.org, Vol. 2 No. 4 